\title{
LOS CONFLICTOS DE LA MODERNIDAD: LA ELITE POLÍTICA EN PUERTO RICO, 1898-1904
}

\author{
POR \\ MARÍA DOLORES LUQUE \\ Universidad de Puerto Rico, Río Piedras
}

\begin{abstract}
Análisis de los significados del 98 a partir del estudio de la aceptación de la elite puertorriqueña, que en esa coyuntura vió la oportunidad de realizar un proyecto modernizador bajo la égida de Estados Unidos. El liberalismo democrático del imperio posibilitaría la puesta en marcha de una reorganización del país que, sin embargo, chocó con las condiciones particulares y estructuras económicas, sociales y culturales de Puerto Rico. Aceptando la consecución de algunos logros, cabe preguntarnos para qué se hicieron y quiénes se beneficiaron de ellos.
\end{abstract}

Cuando en 1898 las tropas norteamericanas desembarcaron sorpresivamente en Guánica - un pequeño pueblo ubicado en la costa sur de la Isla - fueron recibidas por la población con grandes muestras de efusividad y generosidad. Conforme el ejército invasor avanzó por los pueblos del litoral las reacciones se asemejaron. Por ejemplo, Francisco Mejías - alcalde de Yauco, hacendado cafetalero y miembro de una de las familias más prominentes de la localidad- llamó a la invasión "la más hermosas de las fiestas donde brilla el Sol de América", y exclamó que por la "milagrosa intervención del Dios de los justos", los puertorriqueños, habían sido "devueltos al seno de su Madre Americana, en cuyas aguas nos colocara la naturaleza". El comandante norteamericano que tenía a cargo la operación militar de esa ciudad corroboró en su informe oficial el júbilo de la población. Relata lo siguiente: "Bienvenida tan entusiasta no la recibió jamás ninguna tropa: calles y plaza pública no 
podían contener a las multitudes, que daban vivas a los Estados Unidos, a su Presidente y al Ejército norteamericano."1

La historiografía puertorriqueña ha intentado ofrecer respuestas a la actitud de los puertorriqueños en 1898. ¿Por qué ese cambio tan abrupto de un pueblo que anteriormente festejaba la inauguración del gobierno autonómico español y meses más tarde se arrojaba súbitamente en brazos del invasor? En un iluminador ensayo Gervasio García señala que esta conducta no se debió "a un desorden genético ni a una descomposición moral instantánea". Ofrece tres razones fundamentales: 1. la dominación norteamericana no contradijo la ideología autonomista; 2 . favoreció al sector más poderoso y de mayor peso político entre los criollos: los azucareros y 3. coincidió con la voluntad popular ${ }^{2}$.

Por otra parte, los trabajos de Astrid Cubano demuestran cómo el descenso del precio del café en el mercado internacional, a fines de la década de 1890, afectó al sector cafetalero y a los medianos y pequeños agricultores. Estos, en contraposición a los hacendados azucareros, se habían caracterizado por su conservadurismo político debido a su dependencia del comercio con España y Cuba y en las redes crediticias de las grandes casas mercantiles propiedad de peninsulares, que controlaban económica y políticamente la región cafetalera. Como consecuencia de la crisis y de la inminencia de la guerra con los Estados Unidos, estas casas comerciales congelaron el crédito a los caficultores y agricultores, comenzaron a ejecutar las fincas endeudadas y a transferir sus capitales a España, lo que causó un gran desasosiego y profundo malestar entre los propietarios de tierra. Por consiguiente, afirma la autora que no debe sorprender que al llegar el ejército invasor norteamericano "encontró una amplia clase propietaria simpatizante, $\mathrm{o}$ al menos indiferente" 3 .

\footnotetext{
1 María Dolores LUQUE DE SÁNCHEZ, La ocupación norteamericana y la ley Foraker (La opinión pública puertorriqueña) 1898-1904, Río Piedras, Editorial Universitaria, 1980, p. 28; Albert GARDNER ROBINSON, The Porto Rico of Today, New York, Charles Scribner's Sons, 1899, p. 34; Angel RIVERo, Crónica de la Guerra Hispano Americana en Puerto Rico, Madrid Sucesores de Rivadeneyra, 1922, pp. 217 y 218.

2 Gervasio Luis GarCía, "Puerto Rico en el 98: Comentario sobre el informe Carroll" en Historia crítica, historia sin coartadas. Algunos problemas de la historia de Puerto Rico, Río Piedras, Ediciones Huracán, 1985, pp.123-124.

3 Astrid Cubano Iguina, "La política de la elite mercantil y el establecimiento del régimen autonómico en Puerto Rico, 1890-1898", Op. Cit., Boletín del Centro de Investigaciones Históricas, núm 3, Facultad de Humanidades, Universidad de Puerto Rico, Re-
} 
Tomando como punto de partida estas interpretaciones, que se complementan, me interesa destacar el papel que jugó la elite política insular - integrada en su mayoría por profesionales, hacendados y comerciantes - en el proyecto de modernidad que en 1898 auguraba la nueva metrópoli. Para este grupo la modernidad significaba un variado espectro de aspiraciones. En el aspecto política implicaba, entre otras cosas, el establecimiento de estructuras de gobierno democráticas, apertura a nuevas formas de organización y asociación política, la práctica del sufragio electoral. En el aspecto socioeconómico significaba la defensa del librecambismo, el desarrollo de la infraestructura del país, la implantación de los nuevos adelantos tecnológicos, el fomento de la educación y de las artes y la aplicación de los descubrimientos científicos al campo de la salud pública.

\section{LA RUTA HACIA LA MODERNIDAD}

A pesar de las cortapisas impuestas por el gobierno colonial español, Puerto Rico, al igual que muchos países latinoamericanos con características similares, inició lentamente la ruta hacia la modernidad durante el último tercio del siglo 19. De manera limitada algunos logros se alcanzaron en estas décadas como, por ejemplo, el establecimiento de bancos, la introducción de algunas modernas maquinarias agrícolas, la instalación del cable submarino y la construcción de un sistema ferroviario.

En el campo de las artes y de la cultura también hubo avances que, por ejemplo, se reflejaron en nuevas formas urbanísticas y arquitectónicas, la proliferación de periódicos, gabinetes de lecturas y movimientos literarios influidos por las tendencias del modernismo. En el plan de estudio de los colegios públicos y privados de la Isla se reforzó la enseñanza de la física, la química, la botánica y las matemáticas, conforme a la consigna de la época de que los avances científicos abrían el camino al progreso, que era sinónimo de cambio y prosperidad de la sociedad.

cinto de Río Piedras, 1987-1988, pp. 169-173 y "Puerto Rico a finales del siglo XIX", Conferencia en la Universidad de Extremadura-CEXECI, Seminario "Las Antillas españolas de siglo a siglo: Puerto Rico", 22-26 de julio de 1996, trabajo inédito. 
Como resultado de este proceso, para fines de la centuria existía en Puerto Rico un grupo nutrido de criollos profesionales preparado en disciplinas como las ciencias, el magisterio, las leyes y las artes liberales, que había recibido su educación primaria en la Isla y luego había proseguido estudios en universidades europeas y norteamericanas. La mayoría era descendiente de la clase propietaria ya que era la que disponía de los recursos económicos para brindar una educación esmerada a los hijos y, por otra parte, aspiraba a que éstos jugaran un papel prominente en todos los órdenes de la vida del país. Dicho grupo se centró mayormente en las zonas urbanas donde mediante la cátedra, el periodismo y la participación activa en la vida política, impulsaron y lucharon por reformas de corte liberal- moderado y radical, cuyo objetivo principal fue la modernización total del país ${ }^{4}$.

Convencidos de su rol en la sociedad figuraron como oradores y líderes políticos del reformismo y del autonomismo y como columnistas de los periódicos y revistas de mayor circulación en la Isla. A través de los medios informaban al público las novedades acaecidas en la esfera mundial, divulgaban los inventos estrenados y las innovadoras formas de comercio e industrialización en el mundo...

Así a través de la letra y la tribuna, estos hombres comunicaron sus ambiciones redentoristas, no sólo condenando las injusticias sociales... sino actuando como agentes del progreso económico del país...5

Bradford Burns explica para el caso de América Latina que los modelos que sirvieron de inspiración a las elites latinoamericanas en sus proyectos reformistas fueron los países europeos altamente industrializados - Inglaterra, Francia y Alemania- y los Estados Unidos. Ellas atribuían la prosperidad de los Estados Unidos a dos

4 Angel Quintero Rivera, Patricios y plebeyos: burgueses, hacendados, artesanos y obreros. Las relaciones de clase en el Puerto Rico de cambio de siglo, Río Piedras, Ediciones Huracán, 1988, pp. 195-196; Libia M. GonZALEZ, "Progreso y modernidad las ferias de fin de siglo y los hombres de letras en Puerto Rico" en Consuelo NARanjo, Miguel A. SAMPER-Puig y Luis Miguel García Mora (eds.), La nación soñada: Cuba, Puerto Rico y Filipinas ante el 98, Madrid, Ediciones Doce Calles, 1996, 539-546; Manuel Alvarado, "Román Baldorioty de Castro, el voceador de la esperanza", discurso pronunciado en la conmemoración del natalicio de Román Baldorioty de Castro, Universidad de Puerto Rico, Recinto de Río Piedras, 12 de febrero de 1997; María de los Angeles CASTRo ARroyo y María Dolores LuQUe DE SÁNCHEZ, Puerto Rico en su historia, ecología, geopolítica y sociedad, Río Piedras, Editorial La Biblioteca, para publicación.

5. GonZaleZ,[4], p. 540.

R. I., 1997, n. ${ }^{\circ} 211$ 
factores importantes: la preponderancia de los europeos en la composición racial de la población y en la adopción de las ideologías políticas y económicas europeas. Es decir, que los Estados Unidos representaban ante sus ojos el triunfo de la europeización en el Nuevo Mundo ${ }^{6}$. Esto cobró una particular relevancia en el caso de Puerto Rico ya que al sentimiento de admiración se añadía la realidad del vínculo económico del comercio azucarero que a lo largo del siglo 19 había estrechado la relación de la Isla con ese país. Chiles señala lo siguiente:

To some Puerto Ricans the United States appeared as a free country, a country of the Puritans who with the Bible in hand and a prayer on their lips crossed valleys and mountains conceiving great hopes of liberty and redemption. It was thought as a young country with powerful energies, developing with amazing rapidity... Washington represented Cato and Lincoln appeared as the Redeemer.

Liberty and order were pictured as the ideas of that country...Thousands have emigrated from Europe to the promised land dreamed of by humanity. In less than a Century that tribe of Puritans turned into a powerful nation which amazed the world with its invention, progress and respect for the law?

\section{AUTONOMÍA Y MODERNIDAD}

El proyecto de modernidad de la elite política puertorriqueña quedó plasmado en la plataforma del Partido Autonomista Puertorriqueño, creado en 1887, en la ciudad de Ponce. El programa fundacional marcó, además, la pauta para el debate político puertorriqueño en las primeras décadas del siglo 20.

6 E. BRADFORD BuRns, "Cultures in Conflict: The Implication of Modernization in Nineteenth Century Latin America" en Virginia BERNHARD (ed.), Elites, Masses and Modernization in Latin America, 1850-1930, Austin, University of Texas Press, 1979, pp. 11-79.

7 Paul Nelson ChILES, The Puerto Rican Press Reaction to the United States, 1888 1889, Philadelphia, 1944, p. 86. Sobre las relaciones económicas entre Puerto Rico y los Estados Unidos durante el siglo 19 véase el ensayo de Gervasio Luis GARCIA, "Strangers in Paradise? Puerto Rico en la correspondencia de los cónsules norteamericanos (18691900)", Op. Cit., Revista del Centro de Investigaciones Históricas, núm. 9, Facultad de Humanidades, Recinto de Río Piedras, 1997, 27-55. 
Los delegados de los pueblos que asistieron a la Asamblea Constituyente del Partido representaban a los propietarios criollos más importantes del país. También tuvo una participación destacada un numeroso grupo de profesionales, en el que predominaron los médicos y los abogados.

A pesar del proyecto común que los animaba, en el interior de la colectividad se perfilaban disensiones profundas que afectarían la unidad del partido en la próxima década. Desde el principio se plantearon dos tendencias generales: una radical, otra de corte moderado, y dentro de cada una de ellas había diversidad de matices y enfoques.

Los autonomistas radicales defendían la autonomía absoluta al estilo del Canadá. Ellos tenían gran admiración por el tipo de gobierno de la república federada, cuyo modelo por excelencia eran los Estados Unidos. El periódico El Buscapié así lo señalaba:

Somos republicanos y aspiramos a una forma de gobierno y de administración como la que existe en los Estados Unidos, pero la queremos siendo españoles y para España entera, que no es ni puede ser incompatible con el espíritu democrático de la época actual ni con los progresos de la política ${ }^{8}$.

En ese artículo, hacían referencia al movimiento anexionista cubano y rechazaban que en Puerto Rico existiera esa aspiración e incluso condenaban "sin reservas de ningún género la tendencia anexionista." A pesar de estas manifestaciones oficiales, dentro del ala radical autonomista se encontraban miembros que favorecían el anexionismo y posteriormente sus actuaciones se encaminaron hacia esa alternativa. Tampoco se puede descartar la existencia de un núcleo dentro de este grupo que favorecía la separación tanto de España como de los Estados Unidos, como por ejemplo, Sotero Figueroa, quien marchó hacia Nueva York y fue miembro de la Sección Puerto Rico del Partido Revolucionario Cubano. Uno de los fundadores del Partido Autonomista, Félix Tió Malaret, comentaba que:

Casi todos los nativos de influencia en el país por su cultura, tenían también sentimientos separatistas. $\mathrm{Y}$ aunque procuraban ocultar sus sentimiento por temor al destierro o la prisión, se desbordaban, sin em-

8 El Buscapié, 14 de agosto de 1887.

R. I., $1997, \mathrm{n}^{\circ} 211$ 
bargo, en ocasiones sin poderlo evitar... no era contra las personas dicho sentimiento, sino contra la dominación de un país que consideraba inferiores a los habitantes de la Isla ${ }^{9}$.

La tendencia moderada, que fue la que triunfó en la Asamblea, propulsaba la asimilación política y amplia descentralización económico-administrativa. La asimilación política implicaba que se le hicieran extensivos a la Isla los mismos derechos civiles, políticos y jurídicos que gozaban los habitantes de la península. Se incluía también el derecho de enviar representantes locales a las Cortes, lo que aseguraba la participación criolla en la votación de los presupuestos nacionales y en la aprobación de las leyes generales de la nación. En el plano económico administrativo demandaban que las cuestiones locales se resolviesen en la Isla mediante la Diputación Provincial y los municipios "con el concurso legal de sus habitantes." Esto último se concretaba por medio del derecho al sufragio electoral ${ }^{10}$.

Aparte de las diferencias señaladas persistieron otras tensiones: el ala moderada favorecían la asociación con los partidos monárquicos de la metrópoli a los fines de adelantar la causa de la autonomía y la radical rechazaba de plano la idea debido a sus convicciones republicanas y al escepticismo que le provocaba los partidos monárquicos en cuanto a la política colonial. Abonaba a estas diferencias el recelo con que los miembros favorecedores de la asimilación política miraban a aquellos más progresistas, entre los que se encontraban los hacendados azucareros, quienes defendían el librecambismo que les daría el acceso sin trabas onerosas al mercado norteamericano. Estos abogaban por la creación de bancos agrícolas e hipotecarios y la inversión de capitales extranjeros, instrumentos necesarios para la transformación de las haciendas en modernas unidades de producción como eran las centrales ${ }^{11}$.

9 René JimÉnez Malaret, Epistolario histórico del Dr. Félix Tió y Malaret, Santurce, Puerto Rico, s.e.,1953, p. 19.

10 Véase Plan de Ponce para la reorganización del Partido Liberal de la provincia y Acta de la Asamblea Constituyente del Partido Autonomista. Introducción por María de los Angeles CASTRO, edición facsimilar, San Juan, Instituto de Cultura Puertorriqueña, 1991; Pilar BARBOSA Del RosARIO, De Baldorioty a Barbosa. Historia del autonomismo puertorriqueño, San Juan de Puerto Rico, 1957.

11 María de los Angeles CASTRO, "El autonomismo en Puerto Rico (1808-1898): la siembra de una tradición", Secuencia, Revista de Historia y Ciencias Sociales, núm. 31, Instituto Mora, México, 1995, pp. 16-17. 
La posición del sector azucarero se explica en el contexto de la grave crisis económica que asoló la Isla a partir de la década de 1880 provocada por la caída de los precios del azúcar a nivel internacional. Los hacendados desprovistos de capital suficiente, de adecuadas fuentes crediticias y asfixiados por las tarifas proteccionistas impuestas por España se les imposibilitaba competir favorablemente en el mercado mundial. La devaluación de la moneda, la precaria infraestructura del país y la pesada carga del sistema contributivo, entre otras cosas, agravaba aún más la situación. Los comerciantes exportadores experimentaban también los efectos de la crisis y se hicieron eco de las protestas de los hacendados azucareros. A su vez, sectores urbanos, como los funcionarios menores y artesanos, se sumaron a la causa autonomista debido a que sus condiciones de vida y trabajo deterioraban rápidamente por el encarecimiento del costo de vida. Por otra parte, los profesionales, quienes por su nivel de educación se consideraban tanto o más cualificados para dirigir y tomar decisiones sobre la administración del país que los burócratas peninsulares enviados desde la metrópoli, hicieron causa común con los intereses azucareros y comerciales. Para todos estos grupos era de vital importancia alcanzar la autonomía administrativa ya que sería el instrumento clave para impulsar el progreso y la prosperidad del país ${ }^{12}$

Conforme avanzó la década de 1890 afloraron las disensiones dentro del autonomismo, en particular el debate sobre la conveniencia de concertar un pacto con los partidos de la metrópoli a los fines de expeditar la concesión de la autonomía para la Isla. En 1896 se concertó la fusión del Partido Autonomista con el Partido Liberal Fusionista de Práxedes Mateo Sagasta, cuya consecuencia fue la división de las filas autonomistas en dos nuevos partidos políticos: el Partido Liberal Fusionista y el Partido Autonomista Histórico u Ortodoxo, que rechazaba de plano la fusión con un partido monárquico y abogaba por una alianza con los partidos republicanos de la

\footnotetext{
12 Ibidem, p. 18; Astrid T. CUBANO, "Paz pública y propiedad territorial: la discusión sobre política agraria en Puerto Rico, 1880-1889", Op. Cit., Boletín del Centro de Investigaciones Históricas, núm. 5, Universidad de Puerto Rico, Recinto de Río Piedras, 1990, p. 34. Para una discusión más amplia sobre el tema de la crisis azucarera, véase Andrés Ramos Mattei, La hacienda azucarera. Su crecimiento y crisis en Puerto Rico (Siglo $X I X)$, San Juan, CEREP, 1981; del mismo autor, La sociedad del azúcar en Puerto Rico, 1870-1910, Río Piedras, Universidad de Puerto Rico, 1980.
} 
metrópoli ${ }^{13}$. El estallido de la guerra en Cuba precipitó los acontecimientos y en noviembre de 1897 España le concedió el gobierno autonómico a Puerto Rico.

La Carta Autonómica estableció un gobierno compuesto de un Parlamento Insular — dividido en dos cámaras, el Consejo de Administración y la Cámara de Representantes - y de un gobernador nombrado por la metrópoli. El Consejo de Administración estaba integrado por 15 miembros, de los cuales 8 eran de carácter electivo y siete designados por el rey. La Cámara era totalmente electiva mediante el sufragio universal masculino. Además, se le reconocían a los criollos los mismos derechos individuales que a los peninsulares $^{14}$. Al celebrarse las elecciones para constituir el nuevo gobierno, triunfó por una mayoría considerable, el Partido Liberal Fusionista, acaudillado por el periodista Luis Muñoz Rivera ${ }^{15}$.

Así, pues, cuando en el 1898 las tropas norteamericanas invadieron a Puerto Rico encontraron que existía una profunda división política entre los criollos y un gran malestar producto de la crisis económica. Diferentes sectores de la Isla, creyéndose liberados de las restricciones del régimen colonial español y confiados en los valores de la democracia norteamericana, se apresuraron a delinear sus aspiraciones modernizantes ante las nuevas autoridades. La elite política criolla asumió un papel protagónico fundamentado en el ideario autonomista decimonónico.

\section{EL ESPEJISMO DE LA MODERNIDAD}

Al establecerse el gobierno militar norteamericano, los partidos insulares se disolvieron: el Liberal Fusionista se transformó en Par-

\footnotetext{
13 Pilar Barbosa del Rosario, La Comisión Autonomista de 1896. Historia del autonomismo puertorriqueño, San Juan de Puerto Rico, 1957, cap. Vll.

14 Puerto Rico, leyes fundamentales, nueva edición revisada por Alfonso L. GARCIA MARTineZ, Río Piedras, Editorial Edil, 1978.

15 Sobre la figura de Muñoz Rivera y la política puertorriqueña de fines de siglo 19 véase los siguientes ensayos de Astrid CUBANO: "Reformas electorales y práctica política en Puerto Rico (1874-1904)", Seminario sobre Reformas electorales en España y América Latina, 1870-1930, Instituto Universitario Ortega y Gasset y Universidad de Cantabria, Santander, 2-3 de mayo de 1996, trabajo inédito y "El autonomismo en Puerto Rico, 18871898: notas para la definición de un modelo de política radical", en NARANJO, PuIGSAMPER y GARCíA MORA, [4], 406-415.
} 
tido Federal y el Autonomista Histórico en Partido Republicano. Si examinamos sus respectivos manifiestos durante los meses que siguieron a la invasión a primera vista parece no existir grandes diferencias en el contenido de los mismos. El liderato de ambos partidos proclamó la anexión a los Estados Unidos como la aspiración política predominante. Así, por ejemplo, figuras destacados del Partido Republicano declararon en El País, periódico oficial de esa colectividad, lo siguiente:

Puerto Rico recibió con simpatía a los invasores, aceptó con agrado el cambio de soberanía, conducta que se explica por la opresión que padecía la Isla bajo España, por los antecedentes históricos que presentan al pueblo de los Estados Unidos como el más libre y mejor regido de la tierra y por la fundada esperanza de ver cumplidos dentro de nación tan democrática, sus tradicionales anhelos de libertad, igualdad y justicia.

Encontramos en Estados Unidos la forma de gobierno republicana que siempre conceptuamos la más capaz de infundir en una nación la vivificante savia de aquellas virtudes...

Aspiramos a [ser]...un Estado más dentro de la unión para afirmar la personalidad del pueblo puertorriqueño ${ }^{16}$.

De esta manera los antiguos autonomistas ortodoxos reafirmaban su credo republicano federalista, esta vez dentro de la Nación que para ellos representaba el modelo de esa avanzada forma de gobierno.

Asimismo Luis Muñoz Rivera declaró ante el reverendo Henry K. Carroll - quien encabezaba una importante comisión nombrada por el Presidente McKinley- que la incorporación de Puerto Rico como estado de la Unión americana constituía la aspiración suprema de los puertorriqueños ${ }^{17}$.

Sin embargo, este consenso entre el liderato puertorriqueño a favor de la anexión estaba profundamente enraizado en las ideas del autonomismo decimonónico. Líderes republicanos como Santiago Veve, médico y hacendado azucarero, pidieron el establecimiento del sistema territorial de gobierno norteamericano, adaptándolo a las

16 El País, 22 de octubre de 1898; Luis M. DíAz Soler, Rosendo Matienzo Cintrón: orientador y guardián de una cultura, México, Editorial Cultural, 1960, 2 vols., I, pp. 163-164.

17 Henry K. CARroll, Report on the Island of Porto Rico, Washington, Government Printing Office, 1899, p. 234.

R. I., $1997, \mathrm{n}^{\circ} 211$ 
condiciones especiales de la Isla ${ }^{18}$. En las audiencias públicas celebradas por la Comisión Carroll, una de las peticiones principales fue el tradicional reclamo por la autonomía municipal que incluía la elección de los funcionarios mediante el sufragio, el control fiscal y el poder de hacer empréstitos para obras públicas ${ }^{19}$.

La impronta del ideal autonomista fue más patente en el Partido Federal y con originalidad propugnó la concesión del sistema territorial de gobierno de manera diferente a la tradición norteamericana. En dicho sistema los territorios no elegían sus propios gobernadores ya que éstos eran nombrados por el Presidente y los acuerdos de sus legislaturas tenían que contar con la sanción del Congreso. El Partido Federal, en cambio, demandaba que a Puerto Rico se le otorgara el poder de elegir su propio gobernador y que las leyes fuesen aprobadas solamente por la legislatura insular. Más aún, si se llegaban a la identidad con los Estados Unidos aspiraban a tener un gobierno autónomo en el cual los puertorriqueños pudieran regir su destino político. Muñoz Rivera lo expresaba claramente:

Somos regionalistas de igual manera y con igual derecho que lo son en los Estados Unidos de América las varias partes del conjunto glorioso. Pero lo somos proclamando y defendiendo la unidad federal, que constituye la fórmula suprema de nuestros ideales. No acariciamos el sentimiento de la nación como un todo centralizado bajo el imperio de un solo poder gubernativo y legislativo sino el sentimiento de la región, intenso, profundo, de la región constituida y organizada con sabia independencia en la forma de Estado Federal, con gobierno propio, ligándose, uniéndose dentro de una admirable variedad a las otras regiones para obtener como soberana resultante un poder central que garantice la autonomía de los poderes locales y proteja y levante los intereses económicos por la acción de un organismo, fuerte y respetable ${ }^{20}$.

\footnotetext{
18 Ibidem, p. 793; LUQUE DE SÁNCHEZ [1], pp. 56-59. El sistema territorial antecedía a la incorporación definitiva de un territorio a la Unión norteamericana. Implicaba la concesión de la ciudadanía norteamericana, el libre comercio con los Estados de la Unión y el derecho de enviar un Delegado al Congreso sin voto. La administración política podía variar en cada caso ya que dependía de las circunstancias particulares de los territorios. Véase para este tema José TRIAS Monge, Historia constitucional de Puerto Rico, Río Piedras, Editorial Universitaria, 1980-1994, 5 vols, V, pp. 94-98.

19 CARroll, [17], pp. 584-585.

20 Diario de Puerto Rico, 5 de enero de 1900; LuQue De SÁnCHEZ, [1], p. 81.
} 
Recalcaba que los puertorriqueños querían ser americanos, pero salvando los principios regionales, y no haciendo del pueblo "una masa servil de ilotas de levitas"21 Es decir, demandaban de los Estados Unidos lo que tradicionalmente habían solicitado de España: el reconocimiento de unas condiciones y particularidades especiales de la Isla, que significaban un profundo sentido de diferenciación regional con la metrópoli.

Hasta la llegada de los norteamericanos el sector separatista había operado desde el exterior o en la clandestinidad. El grupo estaba integrado por profesionales y hacendados azucareros, particularmente los de la región sur y el oeste de la Isla. En esta zona se concentraba el mayor número de haciendas azucareras de propietarios criollos, quienes desde 1880 sufrían los embates de la crisis que afectaba la industria. Entre los hacendados azucareros identificados con la causa separatista se encontraban figuras prominentes como Eduardo Lugo Viñas, Celedonio Carbonell, Mateo Fajardo y Ricar-do Nadal.

Lugo Viñas se había educado en París y en Nueva York donde cursó estudios de comercio e hizo gestiones para obtener la ciudadanía norteamericana. Era presidente de la Asociación de Agricultores y propietario de la hacienda Carlota, en Guayama, que era la de mayor producción de azúcar moscabada en la Isla ${ }^{22}$. Celedonio Carbonell figuraba como propietario de la hacienda Restauración, en Ponce, y había participado en la Revolución de Lares en 1868. Mateo Fajardo desde hacía 27 años era ciudadano norteamericano. Estudió medicina en Columbia University, Nueva York, y era dueño de las centrales San José y Eureka, esta última localizada en Mayagüez. Por último, Ricardo Nadal, oriundo también de Mayagüez, era ingeniero y dueño de la firma comercial Nadal y Cía. Los cuatro abrazaron el anexionismo e ingresaron en el Partido Republicano. Nadal declaró ante la Comisión Carroll que uno de los motivos principales del movimiento anexionista en la Isla había sido la certeza de que

${ }^{21}$ La Democracia, 5 de febrero de 1900; Luis MuÑoz Rivera, Campañas políticas, 2 vols., Madrid, Editorial Puerto Rico, 1925, I, pp. 242-243.

22 First Annual Register of Porto Rico. San Juan, 1901, p. 59; Jaime A. BAGUE, Del ingenio azucarero patriarcal a la central azucarera corporativa, Mayagüez, Colegio de Agricultura y Artes Mecánicas, 1968, p. 35.

R. I., $1997, \mathrm{n}^{\circ} 211$ 
bajo el régimen norteamericano el azúcar de Puerto Rico entraría libre de impuestos en los Estados Unidos ${ }^{23}$.

Según existió consenso entre el liderato criollo en cuanto a la anexión, asimismo en el plano económico la demanda unánime fue la concesión del comercio libre entre los Estados Unidos y Puerto Rico. En su proyecto modernizador el cabotaje era la base fundamental de la transformación económica del país. Además, insistieron en la necesidad de introducir modernas maquinarias, nuevas técnicas de cultivo y en el establecimiento de un sistema eficiente de transportación para facilitar la circulación de los productos agrícolas hacia los puertos de embarque.

Por su parte. el Partido Incondicional Español, identificado con los grandes intereses económicos peninsulares, en particular las casas comerciales, inicialmente miraron con recelo la transformación que ocurría en el país. No obstante se aprestaron a proteger sus bienes y a participar de las bendiciones que auguraba el nuevo régimen, como era la posibilidad del librecambismo con los Estados Unidos. Además, algunas de estas firmas comerciales habían invertido dinero en haciendas azucareras, como fue el caso de la compañías Roses, propiedad de mallorquines, establecida en Arecibo desde las últimas décadas del siglo $19^{24}$. Un testimonio revelador fue el de Miguel Arsuaga, miembro de Sobrino de Ezquiaga, firma comercial y bancaria, vinculada estrechamente al Partido Incondicional ${ }^{25}$. Arsuaga calculaba que el comercio libre con los Estados Unidos no sólo sería favorable para la prosperidad del país sino que se convertiría en un instrumento de asimilación de los puertorriqueños a los usos y costumbres de los norteamericanos ${ }^{26}$. La perspectiva del libre comercio era afín también a sus intereses en el negocio azucarero. Desde 1850 su compañía era propietaria de la hacienda Buena Vista, situada al norte de la Isla, en el área de Carolina. En 1882 la hacienda se transformó en central y para fines de la década de 1890 poseía 1,400 cuerdas de tierras sembradas de caña y producía 4625 toneladas de azúcar. En 1910 adquirió la Central Progreso ${ }^{27}$.

\footnotetext{
23 CARroll, [17], p. 69.

24 Cubano,[3], p.173.

25 Ibidem, p. 155.

26 CARroll, [17], pp. 148-149.

27 Juan A. GIUSTI-CORDERO, "Labor, Ecology and History in a Caribbean Sugar Plantation Region: Piñones (Loiza), Puerto Rico, 1770-1950", Tesis doctoral sometida a la
} 
El proyecto económico de la elite política se centró más en la modernización de los modos tradicionales de producción agrícola que habían caracterizado a la Isla, como los cultivos de azúcar y café, que en la concepción de un desarrollo total de industrialización para el país. Es decir, que las peticiones de cabotaje y mejoras de la infraestructura insular estuvieron abocadas al fomento agrícola insular.

El liderato criollo no limitó su agenda al plano político y económico sino también en el aspecto social aspiraba a mejorar las precarias condiciones de vida de la masa del pueblo. Para contrarrestar los males que la aquejaban - salarios irrisorios, interminables jornadas de trabajo, problemas de salud, vivienda infrahumana- se contaba con la introducción del capital norteamericano que proveería empleos y aumentaría los salarios. Pero más importante aún para la elite era la implantación de un sistema de educación compulsorio. Félix Matos Bernier, abogado y miembro del Partido Liberal, señalaba que esta medida era la que salvaría a la clase trabajadora de la ignorancia y del atraso $^{28}$.

Muy pronto la americanización del país se asoció con un proyecto progresista y moderno. El connotado líder separatista Eugenio María de Hostos, quien era un admirador de las instituciones democráticas de los Estados Unidos, fue uno de los primeros en utilizar el término en ese sentido:

Americanizarse en todo esto: Modificar la organización social; cambiar el régimen económico; sustituir uno por uno los principios de organización política a la española con la organización del sistema americano de gobierno.

Simplificar toda la administración pública, empezando por la justicia y acabando por la tributación. Reformar la instrucción y transformar la educación pública.

Modificar las costumbres sociales y políticas llenar de instituciones jurídicas y culturales al país entero ${ }^{29}$.

\footnotetext{
Escuela Graduada de la Universidad del Estado de Nueva York, Binghamtom, 1994, pp. 474-476; Humberto GARCíA-MuÑIZ, "The South Porto Rico Sugar Company: The History of a U.S. Multinational Corporation in Puerto Rico and the Dominican Republic, 19001921", Tesis doctoral sometida a la Escuela Graduada de Artes y Ciencias de la Universidad de Columbia, Nueva York, 1997, p. 114.

28 CARroll, [17], pp. 712, 733 y 766.

29 Eugenio Ma. de Hostos, Madre Isla. Obras completas, 22 vols., La Habana, Cultura, S.A., 1939, 5, p.48.
}

R. I., $1997, \mathrm{n}^{\circ} 211$ 
Hostos favorecía la celebración de un plebiscito mediante el cual el pueblo decidiría si quería o no la anexión. Si salía triunfante la última fórmula, pedía el establecimiento de un protectorado norteamericano por espacio de veinte años, el cual "no sería un protectorado de fuerza y poder, sino un mentorado de libertades y progreso." 30 A estos fines la instrucción pública era uno de los pilares para alcanzar las metas propuestas.

Ante la euforia de los primeros meses del régimen norteamericano la elite política criolla no advirtió que desde la óptica de la nueva metrópoli la americanización podía coincidir en algunos aspectos con sus aspiraciones pero también implicaba serios conflictos y contradicciones que en corto tiempo comenzaron a cuajar. Por motivo de espacio sólo tomaremos algunos ejemplos.

\section{EL DESENGAÑO}

Al elaborarse el tipo de gobierno que se le concedería a la Isla, en las altas esferas del gobierno norteamericano prevaleció una actitud de desconfianza hacia el pueblo puertorriqueño. El Secretario de Guerra, Elihu Root, fue la figura más influyente en este sentido. Root señalaba que la población puertorriqueña no estaba preparada para el gobierno propio ya que tenía unos valores culturales diferentes de los norteamericanos, era en su mayoría analfabeta y de una pobreza extrema. Por consiguiente, tenía serias dudas respecto al grado de participación que se debía otorgar a los puertorriqueños en la administración del país. Aunque reconocía que la Isla contaba con un grupo de personas talentosas, no era suficiente para garantizar la efectividad administrativa. Los puertorriqueños tenían que pasar por un largo período de aprendizaje o tutoría para lograr una amplia participación en la vida política insular. Así, pues, el principio de la tutoría cristalizó en la creación para la Isla de unas estructuras de gobierno centralizadas en las que el poder se ejercía desde la metró-

30 Ibidem, p. 22. El énfasis es mío. 
poli, lo que se alejaba de las aspiraciones del liderato criollo y de la idea del "mentorado" de Hostos"

Cuando en 1900 el Congreso de los Estados Unidos aprobó la ley Foraker comenzaron a desvanecerse muchas de las esperanzas que el liderato criollo había cifrado en el nuevo régimen. Esta ley no cumplió con las expectativas de los puertorriqueños, principalmente en sus demandas de la extensión del sistema territorial, la ciudadanía y el libre comercio. El estatus político de los puertorriqueños se mantenía indefinido; no tenían una nacionalidad reconocida internacionalmente. Se les negaba el derecho que habían tenido bajo la dominación española de enviar representantes con voz y voto al cuerpo legislativo de la metrópoli: el Delegado al Congreso era una figura decorativa ya que no se le reconocía ni el derecho a expresar sus opiniones en el hemiciclo del Congreso. El sufragio electoral se restringió a los varones mayores de 21 años que supieran leer o escribir y que fuesen propietarios. Como si todo esto fuera poco, las estructuras de gobierno quedaron supeditadas a la autoridad del Presidente y del Congreso de los Estados Unidos ${ }^{32}$.

Los poderes legislativos residían en una Asamblea Legislativa que constaba de dos cuerpos: el Consejo Ejecutivo y la Cámara de Delegados. El Consejo Ejecutivo era de nombramiento presidencial y estaba integrado por once miembros, de los cuales seis eran norteamericanos y cinco puertorriqueños. Aparte de las funciones legislativas, los miembros norteamericanos ejercían también las de carácter ejecutivo, pues conformaban el Gabinete del Gobernador. Es decir, desempeñaban los puestos de Tesorero, Procurador General, Auditor, Comisionado de Instrucción, Comisionado del Interior y Secretario. Los proyectos de ley podían originarse en cualquiera de las dos Cámaras, pero para su aprobación tenían que contar con la mayoría de los votos de cada uno de los cuerpos y el consentimiento del Gobernador para luego ser aprobadas por el Congreso ${ }^{33}$.

Estas disposiciones de la Ley Foraker dieron motivos para que la opinión pública de la Isla se pronunciara en contra. Aunque aceptaban complacidos el que la Cámara de Delegados fuese de carácter

\footnotetext{
31 Elihu Root, The Military and Colonial Policy of the United States: Addresses and Reports, collected and edited by Robert BACON and James BROWN SCOTT, Cambridge, Harvard University Press, 1916, p. 184; LUQUE DE SANCHEZ, [1], p. 93.

32 LUQUE DE SÁNCHEZ, [1], pp. 126-128.

33 Ibidem, p. 126; véase también TRÍAS MongE,[18], I, pp. 217-219.
} 
electivo y compuesta exclusivamente por puertorriqueños no ocurría lo mismo con el Consejo. A éste lo tildaban de "exótico" por estar integrado en su mayoría por norteamericanos. Aún antes de ponerse en vigor la ley Foraker ya se profetizaba lo que ocurriría con el trabajo de la Cámara de Delegados: supeditada al Consejo, dominado por norteamericanos, sus gestiones quedarían anuladas ${ }^{34}$. Efectivamente, durante los primeros cuatro años de gobierno civil el liderato político criollo sufrió rudos golpes en su agenda modernizadora para la Isla. Para efectos del tema es necesario analizar la composición de los miembros de la Cámara de Delegados y del Consejo Ejecutivo porque en ambos cuerpos se enfrentaron las visiones del liderato criollo y la de las autoridades oficiales norteamericana sobre el futuro de la Isla.

\section{EL LIDERATO CRIOLLO}

Al inaugurarse el nuevo gobierno, el Partido Republicano copó la Cámara de Delegados y los cinco puestos en el Consejo Ejecutivo debido a que el Partido Federal no aceptó la distribución de los distritos electorales que hizo este organismo y optó por el retraimiento de las urnas hasta las elecciones de $1902^{35}$. No obstante, durante el período de 1900-1904 el perfil de los delegados no cambió.

\footnotetext{
34 Ibidem, p. 136.

35 Las fuentes principales que hemos utilizado para obtener las profesiones, edad y nivel de educación de los miembros de la Cámara de Delegado y del Consejo Ejecutivo son las siguientes: Jovino DE LA TORRE, Siluetas ponceñas. Estudios analíticos de los principales personajes de la ciudad de Ponce, Ponce, s.e.,1900; Ramón Morel CAMPOS, Guía local $y$ de comercio de la ciudad de Ponce, Ponce, s.e., 1895; Liga ProgResista DE PONCE, Album guía de Ponce, Ponce, s.e., 1913; Pedro C. TIMOTHEe (comp.), El consultor, San Juan, s.e., 1929; Carmelo Delgado CinTRÓN, Libro de matrículas del ilustre Colegio de Abogados de Puerto Rico, 1840-1910, Instituto de Historia del Derecho Puertorriqueño, Colegio de Abogados de Puerto Rico, 1970; J. FerReras PAGAN, Biografia de las riquezas azucareras de Puerto Rico. Riqueza azucarera, San Juan, Tipografia de Ferreas, 1902, 2 vols.; Angel MÉNDEZ, El pueblo de Yauco, Yauco, s.e., Puerto Rico, 1910; The Representative Men of Porto Rico, compiled and edited by F.E. JACKSON and Son, s.l., s.e., 1910; Enrique GonZÁlez MENA y Joaquín TElleCHEA, Guía comercial $e$ industrial de la ciudad de Ponce para el año 1904-1905, Ponce, s.e., 1903; Guillermo ATILES GARCíA, Kaleidoscopio, Ponce, s.e., 1905; First Annual Register of Porto Rico, San Juan, s.e., 1901; Ramón H. Guerra, De todo un poco, s.l., Progress Publishing Co., 1912; Manuel MAYORAL BARNES, Ponce y su historia, geopolítica, económica y cultural, Ponce, s.e., 1946.
} 
Los profesionales - abogados, médicos, farmacéuticos e ingenieros- fueron el grupo predominante en la Cámara de Delegados y en el Consejo Ejecutivo. Dentro de esta categoría el grupo mayoritario fue el de los abogados, ya que constituyó el $64 \%$ de las profesiones. Esta tendencia siguió hasta el 1914, es decir, que se mantuvo tanto en los períodos de hegemonía republicana como en los federalistaunionista. No debe sorprender este hecho, pues los abogados ejercieron una influencia notable en la sociedad puertorriqueña durante el último tercio del siglo 19. Figuraron prominentemente en las asociaciones culturales - por ejemplo, el Ateneo-y se destacaron como periodistas y literatos. Además, en el campo político asumieron posiciones de liderato. Así, por ejemplo, al concederse la Carta Autonómica, los presidentes del Consejo de Administración y de la Cámara de Representantes del Parlamento insular fueron abogados. Asimismo estuvieron representados en el Gabinete del Gobernador, al ocupar las Secretarías de Instrucción Pública, Agricultura, Industria y Comercio y Obras Públicas ${ }^{36}$. La gran mayoría había estudiado en universidades españolas. Las excepciones fueron: Ángel Mattei de origen corso, quien se educó en Francia; José de Diego, Juan Hernández López y Pascasio Fajardo recibieron el título en la Universidad de La Habana; y Luis Montalvo Guenard, egresado de National University en Washington. Entre los médicos, destacaron $\mathrm{Ca}$ yetano Coll y Toste y Manuel Zeno Gandía, el primero despuntó como historiador y el segundo en el campo de la literatura.

Al grupo de los abogados siguió el de las personas dedicadas a las actividades agrícolas: hacendados azucareros, hacendados cafetaleros y agricultores ${ }^{37}$. En esta categoría los hacendados azucareros predominaron, particularmente durante el período de 1900-1902. En los períodos eleccionario posteriores al de 1904 , hubo poca variación en su participación en la Cámara de Delegados. Es necesario señalar que algunos hacendados figuraron también en el campo de las profesiones. Entre ellos el doctor Santiago Veve y el abogado

\footnotetext{
36 Rubén NAZARIO, "Negociación en la tradición legal: los abogados y el estado colonial de Puerto Rico, 1898-1905", Tesis doctoral sometida al Departamento de Historia, Facultdad de Humanidades, Universidad de Puerto Rico, Recinto de Río Piedras, 1996, pp. 80-81; véase también Bolívar PAGAN, Historia de los partidos políticos puertorriqueños, San Juan, Librería Campos, 1959, 2 vols, I, p. 20.

37 Entre este último grupo no hemos podido identificar a cuál actividad agrícola específica se dedicaban ya que no figuran como hacendados azucareros ni cafetaleros.
} 
Carlos M. Soler, quien era dueño de la hacienda San Pedro, localizada al norte de la Isla. Otros, aunque no obtuvieron un título formal, asistieron a instituciones educativas en el exterior, como por ejemplo, el patriarca autonomista Francisco Mariano Quiñones -quien estudió en Alemania, Francia, Inglaterra y los Estados Unidos- y Eduardo Lugo Viñas, cursó estudios en París y en Nueva York. Por su parte, los hacendados cafetaleros también desempeñaron otras actividades - por ejemplo, Lucas Amadeo y Francisco Coira, delegados por el distrito de Arecibo, ejercieron el comercio- y Francisco Mejías perteneció a la Junta de gobierno del Banco Crédito y Ahorro Ponceño.

Los comerciantes configuraron el tercer grupo. Estos representaban casas comerciales, establecidas en las ciudades portuarias de Ponce, Aguadilla, Mayagüez, Humacao, Guayama y San Juan. Por último, los periodistas, maestros y otras ocupaciones menores figuraron también en el cuadro político.

Es interesante señalar que entre los delegados a la Cámara durante el período en estudio figuraron 20 miembros que habían sido fundadores del Partido Autonomista, doce provenían del ala radical y el resto del ala moderada de esa colectividad. Además, en la primera Cámara de Delegados, integrada totalmente por republicanos, fueron elegidos 6 miembros separatistas cuyas tendencias anexionistas quedaron fuera de toda duda. Entre éstos se encontraban los miembros de la Sección Puerto Rico del Partido Revolucionario Cubano: el abogado Roberto $\mathrm{H}$. Todd; el comerciante de Ponce, Pedro Besosa y el periodista Tomás C. Maduro. Los tres restantes eran: Aurelio Méndez, comerciante, quien había participado en el Grito de Lares; Pedro Descartes, propietario de Guayama y el hacendado Eduardo Lugo Viñas. Manuel Egozcue, miembro del antiguo Partido Incondicional Español, ocupó también un escaño por el distrito de San Juan. Los norteamericanos recién llegados a la Isla, Frederick Cornwell - abogado, oriundo de San Luis Missouri-y George Fishback - militar voluntario de las tropas invasoras- también fueron electos. El primero formó parte de la delegación del distrito de Mayagüez y el segundo del de Guayama ${ }^{38}$.

38 First Annual Report of the Governor of Porto Rico, Washington, Government Printing Office, 1901, pp. 437-438; Fernando BAYRON TORO, Elecciones y partidos politicos de Puerto Rico (1809-1976), Mayagüez, Editorial Isla, 1977, p. 166. 
El Consejo Ejecutivo siguió el patrón de la Cámara en el sentido de que predominaron los médicos y los abogados. Por ejemplo los miembros del primer Consejo Ejecutivo fueron los doctores José C. Barbosa y José Gómez Brioso y los abogados Rosendo Matienzo Cintrón y José Guzmán Benítez. Con excepción de Barbosa, quien se había graduado de la Universidad de Michigan, el resto había cursado la carrera en España. El quinto miembro era Andrés Crosas, aunque nació en San Juan, se educó en los Estados Unidos y obtuvo la nacionalidad norteamericana. Participó en la Guerra Civil norteamericana y en 1873 regresó a Puerto Rico. Además de ser un próspero comerciante y propietario de tierras, ocupó por muchos años el cargo de cónsul de los Estados Unidos en Puerto Rico ${ }^{39}$. Como se puede apreciar, los puertorriqueños electos a la Cámara de Delegados y los nombrados por el Presidente al Consejo Ejecutivo eran representativos de la élite intelectual y social de la Isla. En su mayoría eran hombres cultos, experimentados en las lides políticas del país y habían tenido amplio contacto con el mundo exterior, particularmente con los países europeos y en menor grado con los Estados Unidos. La edad promedio fluctuaba entre los 30 y 40 años, lo que indica que era un liderato todavía joven.

Por todas estas características no estaban en desventaja frente a los representantes del gobierno norteamericano en la Isla. Las credenciales académicas eran equivalentes, los distanciaba el ejercicio del poder colonial y el choque de valores culturales. Observaba el periódico La Democracia que:

...no seremos Estado quizás dentro de un siglo, lo han dicho y repetido senadores y periodistas americanos. Cuando se discutió el bill [Foraker] que hoy nos rige se dijo que Puerto Rico no estaba en condiciones no ya para ser Estado, pero ni siquiera territorio de la Unión. Dada la diferencia de razas, de costumbres, idioma y hasta la distancia que nos separa del continente americano, lógico es suponer que el pueblo del Norte resistiría siempre a que se nos declare Estado ${ }^{40}$.

39 The Representative Men, [35], p. 87.

40 La Democracia, 3 de enero de 1901.

R. I., $1997, \mathrm{n}^{\circ} 211$ 


\section{LOS CONFLICTOS LEGISLATIVOS}

A pesar del disgusto que reinaba en los diversos sectores de la Isla por las estructuras de gobierno implantadas por la ley Foraker, las cuales resultaban mucho más restrictivas que las de la Carta Autonómica, el liderato criollo una vez en el poder se dio a la tarea de poner en práctica su agenda modernizadora mediante la presentación de proyectos de ley encaminados a reformar la vida socio-económica del país. Pero pronto se percataron que sus intereses chocaban con los de la mayoría norteamericana que dominaba el Consejo Ejecutivo. El periódico El Diario de Puerto Rico comentaba lo siguiente:

El bill Foraker... crea... una legislatura insular electiva; pero pone sobre la legislatura insular, un cuerpo burocrático, en que los puertorriqueños estarán en triste minoría, y un veto del gobernador, que él empleará según le plazca. En el porvenir se entablará la lucha. Y no puede dudarse que los burócratas electos por el Presidente, tomarán la parte del león y reservarán a los insulares la otra parte: la del cordero ${ }^{41}$.

A pesar de que se tildó a la Cámara de Delegados de claudicar ante la voluntad del Consejo Ejecutivo, las relaciones entre ambos cuerpos no estuvieron exentas de conflictos y resistencias que, entre otras cosas, erosionaron la hegemonía del Partido Republicano y acabaron por reforzar el sentido regionalista del liderato criollo. Por limitaciones de espacio tomaremos algunos ejemplos solamente.

Una de las reformas fundamentales por la que había luchado el liderato criollo en el siglo 19 fue la autonomía municipal. Es decir, otorgarle a los municipios el poder de decisión en todo los aspectos de la administración local. Sin embargo, desde la primera asamblea legislativa se aprobaron un número de leyes que atentó contra esta autonomía ya que el gobierno centralizó las funciones administrativas, lo que le restaba poder al liderato criollo municipal.

Los municipios no pueden designar los profesores de sus escuelas porque en la designación interviene el Comisionado de la Enseñanza; ni los médicos de su distrito porque ha de consultarse al Comisionado de Sanidad; ni los vigilantes de sus barrios, porque el gobernador escoge a todos los individuos de la "Insular Police" y no se consiente a los pue-

41 Diario de Puerto Rico, 20 de enero de 1900; MUÑOZ Rivera, [21], vol. I, p. 253. 
blos tener policía propia; ni pueden repartir ni recaudar sus contribuciones, porque de esta función se encarga en absoluto el tesorero de la isla; de modo que en Puerto Rico no hay municipios y hasta las vacantes de alcaldes y concejales han de ser cubiertas por el gobernador ${ }^{42}$.

Un ejemplo claro de esta centralización de poderes fue la ley que implantó el sistema de educación pública en la Isla. Dicha ley fue acogida inicialmente con gran entusiasmo ya que existía consenso en que la educación era uno de los medios indispensables para la modernización y progreso del país. La manera en cómo llevarla a cabo fue lo que se convirtió en una fuente de conflictos.

A estos efectos se creó una estructura administrativa centralizada para la organización del sistema educativo de la Isla. Entre otras cosas, el Comisionado de Educación era norteamericano, nombrado por el Presidente de los Estados Unidos con plenos poderes para la supervisión de la educación. Como parte de la reforma, se trasladaron a Puerto Rico los métodos, las técnicas educativas y el programa general de estudio de los Estados Unidos sin tomar en consideración las condiciones particulares de la Isla. Por ejemplo, los libros de textos que se importaron no tenían pertinencia ni se ajustaban al mundo real de los estudiantes puertorriqueños. Pero el conflicto más espinoso fue la exigencia del idioma inglés. Levantó serias controversias como medida pedagógica y causó, además, un profundo choque cultural que fue objeto de interminables debates durante las décadas siguientes. A pesar de esta imposición los puertorriqueños no claudicaron en su lucha por la defensa del idioma español.

Si bien el número de escuelas creció en el país, el énfasis del gobierno fue en la enseñanza primaria ya que prepararía al grueso de la población para desempeñarse como fuerza trabajadora eficiente. En cambio, la élite puertorriqueña demandaba que se atendiese con igual interés la enseñanza secundaria ${ }^{43}$.

Otra de las leyes conflictivas aprobada por la Asamblea Legislativa de 1901 fue la ley Hollander. Esta medida cumplía con el artí-

42 The Puerto Rico Herald, 13 de julio de 1901; MUÑoz RIVERA, [21], vol. II, p. 3.

43 Sobre el tema véase Aida NegRón DE MONTILlA, La americanización en Puerto Rico y el sistema de instrucción pública, 1900-1930, segunda edición en español, Río Piedras, Editorial de la Universidad de Puerto Rico, 1990; Juan José OsunA, A History of Education in Puerto Rico, Río Piedras, Editorial de la Universidad de Puerto Rico, 1949; CASTRo Arroyo y LuQue de SÁnChez [4]. 
culo 3 de la ley Foraker en el cual se estipulaba la concesión del comercio libre entre Puerto Rico y los Estados Unidos una vez se elaborara un sistema contributivo local ${ }^{44}$. Tal disposición era vital para las aspiraciones de los puertorriqueños, pues cifraban en ella, como ya he señalado, el adelanto y el progreso material de la Isla.

El proyecto de ley Foraker otorgaba inicialmente el comercio libre a Puerto Rico, pero la cláusula fue objeto de largos debates en el Congreso norteamericano. Un sector de los intereses económicos norteamericanos, que incluía diversas asociaciones de Agricultores - tabaco, algodón, frutas y vegetales- y los manufactureros del azúcar de remolacha se opusieron con vehemencia a la concesión del comercio libre. Estimaban que tal disposición significaría la ruptura con el principio del proteccionismo tarifario, que había sido fundamental para el desarrollo de la industria norteamericana. Además, temían sentar un precedente para la admisión sin impuesto de los productos agrícolas - sobre todo el azúcar- de Hawai, las Filipinas y Cuba, que en conjunto representaban una fuerte competencia. A la larga la presión que ejercieron los intereses económicos tuvo éxito ${ }^{45}$.

Por otra parte, también hubo consideraciones prácticas en las discusiones como fue la recaudación de ingresos para el sostenimiento del gobierno insular. La postración económica que sufría la Isla dificultaba sobremanera la recolección de fondos suficientes para este fin. Por todas estas razones, se impuso el $15 \%$ de la tarifa arancelaria aplicable a los artículos procedentes de naciones extranjeras que entraban a los Estados Unidos. No obstante, la ley dispuso que los ingresos por este concepto se pondrían en un fondo separado para utilizarse en beneficio de Puerto Rico y tan pronto la Isla pudiese elaborar un sistema contributivo propio se le concedería el comercio libre.

Así, pues, el 2 de enero de 1901, el Tesorero de Puerto Rico, G.H. Hollander, presentó en el Consejo Ejecutivo un proyecto de ley que imponía tres tipos de contribución: el primero sobre la propie-

44 Puerto Rico: leyes fundamentales, [14], pp. 130-131.

45 Para una discusión sobre el tema véase Lyman J. Gould, La ley Foraker: raíces de la política colonial de los Estados Unidos, 2nda edición, Río Piedras, Editorial Universitaria, 1975, caps. V-Vll; LUQUE DE SÁNCHEZ, [1], cap. IV, pp. 95-131; TRÍAS MONGE, [18], pp. 212-213; Carmen I. RAFFUCCI-GARCIA, El gobierno civil y la ley Foraker, Río Piedras, Editorial Universitaria, 1981, pp. 81-88. 
dad mueble e inmueble, el segundo sobre herencia y el tercero aplicaba varios arbitrios ${ }^{46}$.

Respecto al primer tipo contributivo, el proyecto imponía un $2 \%$ sobre el valor de la propiedad mueble e inmueble. Esto se apartaba de la tradición colonial española en la que se proveía para un impuesto territorial sobre el ingreso neto derivado solamente de la propiedad urbana y agrícola y otro sobre la industria y comercio, que era una licencia especial sobre todas las ocupaciones industriales y profesionales, según el tipo de negocio y la importancia del distrito municipal ${ }^{47}$. El proyecto Hollander disponía también que los socios de casas mercantiles u otros negocios estarían sujetos al pago de contribuciones por todos los bienes muebles empleados en los mismos, incluyendo vapores, buques, botes y lanchas. En caso de que los socios tuvieran negocios en dos o más distritos estarían sujetos al pago de contribución en cada uno de ellos. Además, las mercancías serían tasadas por su valor promedio.

Los arbitrios gravaban los líquidos alcohólicos —destilados o fermentados-, tabaco elaborado, preparaciones medicinales de patentes, naipes, armas de fuego, fósforos, mantequilla de oleomargarina. Por ejemplo, las bebidas alcohólicas destiladas - como whiskey, ginebra, cognac, etc. - que fuesen para venta o consumo en Puerto Rico o que se importasen pagarían 80 ctvos. el galón o fracción de galón. Además, cada comercio al por mayor de bebidas alcohólicas tenía que pagar una licencia anual de $\$ 80.00^{48}$.

El tipo contributivo sobre herencia se fijaba según el grado de parentesco de los herederos con la persona fallecida y el valor del caudal.

Los miembros del Consejo Ejecutivo, con excepción de Andrés Crosas votaron a favor del proyecto y se envió para discusión a la Cámara de Delegados ${ }^{49}$. El voto en contra de Crosas, quien como se-

46 Journal of the Executive Council of Porto Rico, San Juan, Bureau of Printing and Supplies, 1901, pp. 145-146.

47 "Report of the Treasurer of Porto Rico to the Governor of Porto Rico, Covering Operations of the Office of the Treasurer from May 1, 1900, to March 31, 1901", en First Annual Report, [38], p. 149.

48 Leyes y resoluciones de la Primera Asamblea Legislativa de Puerto Rico, San Juan, s.e.,1901, véanse las secciones $9,11,79$, pp. 53,88,89,90,91.

49 Ibidem; La Democracia, 5 de enero de 1901. 
ñalé tenía numerosas propiedades y negocios, auguró el revuelo general que el proyecto causó en la Isla cuando se dio a la publicidad.

Muchos municipios de diversas partes de la Isla - como Mayagüez, Ponce, Río Piedras, Yauco, Guayama, Vega Baja, Caguas, Utuado, San Sebastián—, la Sociedad de Agricultores, la Cámara de Comercio, la Liga de Propietarios, entre otros, protestaron vigorosamente contra el proyecto y pidieron enmiendas al mismo ${ }^{50}$. Asimismo la prensa del país se unió a este coro de voces.

Argumentaron que el país no se había recuperado de la crisis económica de la década de 1890 (caída de los precios del azúcar y del café a nivel internacional, la contracción del crédito, encarecimiento del costo de vida) la cual se había agudizado profundamente por los efectos de la ocupación militar norteamericana. A saber, la Isla perdió los mercados de Cuba y España adonde se exportaban mayormente el café y el tabaco. España, al perder las colonias, clasificó los productos procedentes de ellas como extranjeros y les impuso tarifas arancelarias y Cuba protegió el café y el tabaco de la competencia que le ofrecía la producción de Puerto Rico. Por otra parte al no establecerse el cabotaje los productos puertorriqueños pagaban altos aranceles en el mercado norteamericano ${ }^{51}$.

Como si todo esto fuera poco, en 1899 la Isla sufrió el azote del huracán San Ciriaco, que a su paso dejó un saldo de tres mil muertos y miles de hogares destruidos. Causó graves daños a la agricultura, pues devastó las cosechas, principalmente la del café. El gobernador militar norteamericano, general Davis, señaló que desde 1899 a 1901 la economía cafetalera había experimentado una pérdida de 12 millones de dólares, sin contar el capital acumulado en mercancía. En septiembre de 1899, Davis emitió una orden militar mediante la cual se suspendió temporalmente la recaudación de impuestos en los municipios afectados. Todavía en 1902 los agricultores, principalmente los caficultores, debían 295 millones de pesos al gobierno insular por concepto de contribuciones atrasadas. Mayagüez y Arecibo fue-

\footnotetext{
50 Cámara de Delegados de Puerto Rico, Libro de Actas, Libro I, 1900-1901, 10 de enero de 1901, véase también las pp. 148-161 y 178; La Democracia, 16 de enero de 1901, 17 de enero de 1901,19 de enero de 1901.

51 Carroll, [17], p.769; Geo. W. Davis, Report of Gen. Geo. W. Davis on Civil Affairs of Puerto Rico, Washington, Government Printing Office, 1900, pp. 40-41.
} 
ron los distritos más asolados ya que las fincas de café sobrepasaban el $50 \%$ de las tierras en cultivo ${ }^{52}$.

En este contexto no debe sorprender la reacción de la opinión pública en contra del proyecto Hollander. El periódico La Democracia resumía la situación en los siguientes términos:

Aquí donde la invasión perturbó - como era natural la marcha de la isla; donde la baja en los productos del café mermó tanto los productos exportables; donde el ciclón dejó sus huellas de muerte por largos años, aquí, más que en pueblo alguno, es necesario desenvolver elementos productores, estimular entusiasmo para el cultivo, crear sobre el suelo fértil una nueva riqueza que reemplace a la riqueza que se debilitó o arruinó por la fatalidad.

Y si en vez de propender a esto se propende a lo contrario; si se le esquilma al contribuyente en provecho del burócrata; si se le arranca lo más sagrado de sus frutos con destino al tesoro nunca repleto; si se le abruma con una deuda que no está en condiciones de pagar, surgirán las dificultades y los conflictos y se engendrará una situación que el gobierno debe evitar ${ }^{53}$.

Continuaba argumentando el periódico que si se aprobaba el proyecto Hollander:

...tendremos que el casero aumentará el alquiler de sus casas, y el comerciante el precio de sus efectos, para satisfacer ambos el doble tributo que se le impone, mientras que el agricultor y el industrial, que son los que dan trabajo al pobre, se verán obligados a reducir el jornal; y tendremos que el pobre jornalero ganará menos y pagará más por la habitación que ocupe y por el pedazo de pan que se lleve a la boca ${ }^{54}$.

El debate se agudizó cuando Hollander declaró que el objetivo del proyecto era forzar a los propietarios nativos, demasiado pobres para cultivar sus fincas, a abandonarlas o venderlas a otros más afortunados. Se tildó al Tesorero de ser un economista teórico y de desconocer la situación real del país.

52 Stuart B. SchwARTZ, "The Hurricane of San Ciriaco: Disaster, Politics and Society in Puerto Rico, 1899-1901", Hispanic American Historical Review, vol 72, núm. 3, Duke University Press, 1992, pp. 312, 324, 330.

53 La Democracia, 7 de enero de 1901.

54 La Democracia, 1 de febrero de 1901.

R. I., $1997, \mathrm{n}^{\circ} 211$ 
Si se aprobara su bill, antes de un lustro la mayoría de las fincas habrían pasado de manos de los puertorriqueños a manos de los continentales. Estos una vez fincados, serán los dueños absolutos del país; y tras la emigración de braceros que ya ha empezado, vendría la emigración de los propietarios; y tras éstas la emigración de todas nuestras clases sociales.

El bill Hollander es, pues, el primer puntapié con que se ha de arrojar de este país a un pueblo y una raza ${ }^{55}$.

Aparte de los efectos económicos de la medida, preocupaba quiénes serían los tasadores encargados de evaluar las propiedades. Se temía que se convirtieran en un arma política, pues se rumoraba que en su mayoría eran republicanos, lo que inspiraba suspicacias a los federales. Además, se ponía en tela de juicio la competencia de los tasadores. Por otra parte, la ley determinaba que el Consejo Ejecutivo era el órgano supremo de apelación de las decisiones de los tasadores ${ }^{56}$.

La discusión creó tensiones dentro del Partido Republicano y en la Asamblea Legislativa. José Celso Barbosa -jefe de este partido, médico y miembro del Consejo Ejecutivo-representaba en la Cámara a un sector más progresista dentro del grupo profesional, cuyas ataduras socio-económicas no estaban vinculadas ni al comercio ni a la propiedad de tierras, por lo que defendió la ley en términos de que era un "sistema racional de tributación" que ampliaba la base impositiva. Alegaba que bajo el régimen español los bienes muebles e inmuebles eran fáciles de eludir el pago de tributación y, por eso, el gobierno hacía cubrir el déficit con otros arbitrios ${ }^{57}$.

Cuando la Cámara de Delegados discutió el proyecto una de las alternativas que presentó fue que se le concediese un empréstito a la Isla de 3 millones de dólares y que se emitiesen bonos por dicha suma a un tipo de interés anual del $5112 \%$. El préstamo se dividiría en tres partes iguales y el dinero se depositaría en bancos agrícolas establecidos en tres regiones de la Isla: San Juan, Ponce y Mayagüez $^{58}$. Cuando esta moción no prosperó en el Consejo Ejecutivo, la Cámara de Delegados se mostró firme en que se enmendase el pro-

\footnotetext{
55 La Democracia, 31 de enero de 1901. San Juan News, 9 de enero de 1901.

56 Leyes y resoluciones de la primera asamblea legislativa, [48], Sec. 31. p. 62.

57 El País, 14 de junio de 1901.

58 Cámara de Delegados, [50], 21 de enero de 1901.
} 
yecto Hollander, rebajándose el impuesto contributivo sobre los bienes muebles e inmuebles a $1 \% 59$. Quince delegados votaron en contra del proyecto ${ }^{60}$. Ante la posición de la Cámara y la protesta pública, el Consejo Ejecutivo concurrió en la enmienda. La ley Hollander fue aprobada finalmente el 31 de enero de $1901^{61}$.

No obstante, las "fuerzas vivas" del país convocaron a una magna asamblea en los días siguientes a los fines de protestar sobre la ley. Asistieron al evento 2.000 personas, entre las que se encontraban los mayores contribuyentes y propietarios del país - hacendados, comerciantes y banqueros- así como obreros ${ }^{62}$. Destacaban prominentes figuras del sector azucarero y de los partidos políticos, como por ejemplo, el republicano Carlos Cabrera —dueño de la hacienda Florida en Santa Isabel, miembro de la Junta de Directores de la Central Guánica - y el federalista Carlos M. Soler, abogado, hacendado, vice-presidente del Banco Español y presidente del Banco Comercial de Puerto Rico. Los acuerdos principales que tomó la Asamblea fueron la creación en la Isla de juntas locales para defender los derechos de los contribuyentes y el envío de una comisión a Washington para recabar del Presidente y del Congreso la anulación de la ley ${ }^{63}$. La comisión no tuvo éxito en sus gestiones.

Importantes firmas bancarias y comerciales de Nueva York, que tenían negocios con Puerto Rico dirigieron también sus protestas al Congreso. Calificaron la ley Hollander como "injusta, arbitraria, extremada e inaplicable a las condiciones actuales de Puerto Rico". Firmaron alrededor de 20 compañías, entre ellas se encontraban las siguientes: Muller, Schall and Co., principales banqueros de las Antillas y corresponsales del Banco Colonial Americano de San Juan del cual eran los mayores accionistas; H.W. Peabody and Co., exportadores e importadores y banqueros que comerciaban con todo el mundo, en particular con Australia, Filipinas y las Antillas; Cumming and Stockbridge, una de las más fuertes casa del mundo

\footnotetext{
59 La Democracia, 25 de enero de 1901.

60 La Democracia, 31 de enero de 1901.

61 Las leyes y resoluciones de la primera Asamblea legislativa [48], p. 111.

62 La Democracia, 3 de febrero de 1901.

63 Ibidem; véase Manifiesto circular de la junta nombrada por la magna asamblea de propietarios, hacendados, banqueros, comerciantes y demás representantes de las fuerzas vivas del país, San Juan, s.e., 1901, p. 8.
} 
con sucursales en Londres y Hamburgo ${ }^{64}$. El San Juan News resumía el debate en los siguientes términos:

En síntesis, para las fuerzas vivas, la Ley Hollander representaba el centralismo burocrático y la interferencia estatal en los negocios, dos características normalmente imputadas al régimen colonial español, cuya legislación, en particular la tributaria y comercial, ahora representan las fuerzas vivas criollas como más "burguesa y liberal" que la implantada por el régimen norteamericano ${ }^{65}$.

Estudios recientes defienden la ley Hollander como una medida que respondió a "nociones de racionalidad y modernidad, y al interés de implantar métodos científicos que eliminaran las consideraciones personalistas en los procesos de avalúo y cobro de tributos, y al fomento de relaciones capitalistas." 66 En parte el planteamiento es cierto si se considera sólo el texto de la ley y si se compara con el complejo sistema de tributación colonial español. Pero no podemos olvidar el contexto de crisis en que se aprobó la ley y, por otra parte, queda todavía por hacer un estudio que analice los efectos económicos de la ley Hollander. Hay que recordar que a fines de enero se aprobó la ley y no fue hasta julio que se concedió el comercio libre con los Estados Unidos. Los arbitrios que imponía la nueva ley comenzaron a cobrarse desde febrero de 1901, a pesar de seguir vigente la tarifa arancelaria norteamericana, es decir, que se imponía un doble tributo ${ }^{67}$. Además, la ciudadanía norteamericana, que fue vinculada al libre comercio, quedó relegada y no fue hasta 1917 que se hizo extensiva a los puertorriqueños. El debate sobre la Ley Hollander por un lado demostró la resistencia de la elite política puertorriqueña al poder autoritario de la metrópoli, y por el otro marcó los límites de esa resistencia y puso de relieve su vulnerabilidad económica, que la impulsaba a asumir posiciones tradicionales en contradicción con su proyecto modernizante.

\footnotetext{
64 San Juan News, 1 de marzo de 1901.

65 Ibidem.

66 NAZARIO, [36], pp.234-235; Juan GiUSTI CORDERO, "Hacia otro 98: "el grupo español" en Puerto Rico, 1890-1930 (Azúcar, banca y política)", Op. Cit, Revista del Centro de Investigaciones Históricas, núm. 10, Facultad de Humanidades, Universidad de Puerto Rico, Recinto de Río Piedras, 1997, en prensa.

67 Manifiesto circular de la junta...[63], p. 13.
} 
En 1902 se celebraron las segundas elecciones en el país con la participación del Partido Federal, que ganó los distritos de Arecibo y Humacao. Quizás la explicación del triunfo en Arecibo se debió a que, como señalamos, este fue el distrito que más sufrió los embates del huracán San Ciriaco y, por consiguiente, los caficultores y los agricultores de frutos menores resintieron más la aprobación de la ley Hollander y rehusaron votar por el Partido Republicano. También en Arecibo se encontraban cinco centrales azucareras, entre ellas, la Monserrate de la familia Calaf, que había sido opositora tenaz de la ley Hollander ${ }^{68}$.

Todos estos factores, unidos al disgusto que reinaba debido a las estructuras de gobierno que centralizaban el poder en manos de los norteamericanos, coadyuvaron al debilitamiento del Partido Republicano y a fortalecer el sentido de identidad nacional de la elite puertorriqueña.

\section{EL PARTIDO UNIONISTA}

A partir de 1902 se hizo evidente que dentro de las filas republicanas reinaba el descontento por parte de algunos de sus miembros. Rosendo Matienzo Cintrón, abogado y miembro del Consejo Ejecutivo fue de los primeros republicanos en expresar el disgusto que causaba las acciones del Consejo Ejecutivo. Alegaba Matienzo que la Isla se veía gravemente amenazada por la asimilación norteamericana: "los puertorriqueños no tienen patria y es preciso que se unan todos para contrarrestar la absorción"69. Inició, pues, un movimiento encaminado a la unión de todos los partidos para reformar el régimen. El periódico The Puerto Rico Herald se hizo eco de la crítica al sistema:

El pueblo de Puerto Rico demanda la constitución americana íntegra; la potestad de elegir todos sus funcionarios; de discutir y votar todas sus leyes; de acordar todos sus gastos y de administrar todos sus intereses. Un gobernador que hable la lengua del país; un Consejo que se componga de hijos del país..., unos municipios libres...

\footnotetext{
68 Ibidem.

69 DíAz SOLER, [16], p. 216.
}

R. I., $1997, \mathrm{n}^{\circ} 211$ 


\begin{abstract}
Mientras esto no se dé a Puerto Rico, aumentará de seguro la riqueza; cargarán más azúcar los navíos; crecerá la importación, sobre todo en artículos de lujo, habrá troncos soberbios para los carruajes, y vinos añejos para los banquetes y palabras miel para los discursos.

Pero el pueblo de Puerto Rico seguirá siendo un pueblo esclavo, en una esclavitud tanto más odiosa y absurda cuanto que la sanciona o la consiente el pueblo más libre del mundo ${ }^{70}$.
\end{abstract}

El movimiento unionista cobró fuerza en la Isla y logró aglutinar a importantes sectores de los grupos profesionales, hacendados azucareros y cafetaleros. El Partido Federal y un ala disidente del Partido Republicano le dio el endoso, entre este último grupo se encontraban antiguos separatistas anexionistas, como el centralista Mateo Fajardo, el abogado Roberto $\mathrm{H}$. Todd, el comerciante Ricardo Nadal, y los médicos José Julio Henna y Francisco Basora ${ }^{71}$. De esta manera se fundó, en 1904, el Partido Unionista.

El Partido Unionista reclamó que se definiese de una vez el estatus político de la Isla y que se estableciese un gobierno autonómico mediante el cual el pueblo tuviese la plena capacidad de gobernarse a sí mismo. La base quinta reclamaba como soluciones factibles para la Isla que fuese un Estado de la Unión americana, "medio por el cual puede sernos reconocidos el self-government" o se declarara la independencia "bajo el protectorado de los Estados Unidos, medio por el cual también puede sernos reconocido el selfgovernment que necesitamos y pedimos"72. Esta fue la primera vez que un partido político puertorriqueño incluía la independencia como alternativa para resolver el estatus colonial de la Isla y se le daría amplia participación política a la clase obrera, pues para esta fecha se había concedido el sufragio universal masculino.

Los unionistas tuvieron un triunfo resonante, conquistaron 5 distritos electorales, lo que les dio derecho a 25 escaños en la Cámara de Delegados, de éstos los obreros ocuparon 5. Fueron electos dos tipógrafos, un carpintero, un obrero pintor, un marinero y un periodista $^{73}$.

70 MUÑOZ RIVERA, [21], vol. II, p. 17.

71 DiAZ Soler, [16], pp. 256-258.

72 PAGAN, [36], I, p. 112.

73 BAYRON TORO, [38], pp. 125-126; Gervasio L. GARCIA y A. G. QUINTERo RIVERA, Desafio y solidaridad. Breve historia del movimiento obrero puertorriqueño, Río Piedras, Ediciones Huracán, 1982, p. 52. 
Ángel Quintero señala que el Partido Unionista obtuvo su mayor concentración de votos en las área geográficas del norte, con excepción de las dos ciudades de Bayamón y San Juan, y en el este. También aparecen unos bolsillos de fuerza electoral en la punta oeste la Isla. Una de las muchas posibles explicaciones para esto es que estudios recientes, como los de Juan Giusti y Humberto García, revelan que en esas áreas no penetró el capital norteamericano, como ocurrió en el sur de la Isla donde se establecieron los colosos azucareros de la Central Aguirre y Central Guánica. En cambio, en el norte y en el este se concentraron los centralistas puertorriqueños, peninsulares y otros grupos europeos ${ }^{74}$, por consiguiente, al controlar económicamente el área mostraron una actitud más crítica al régimen.

\section{CONCLUSIÓN}

El 98 pareció significar para la elite política puertorriqueña la oportunidad de llevar a cabo su acariciado proyecto de modernidad. Hubo consenso entre los diversos sectores políticos pues el proyecto que se articuló a raíz de la invasión no fue fruto de la improvisación sino de un largo proceso de maduración colectiva que al mismo tiempo resultó en la expresión de un profundo sentido de diferenciación respecto a los gobiernos metropolitanos. En el imaginario de la elite criolla los Estados Unidos representaron el modelo del liberalismo democrático cuyos recursos morales y materiales podían impulsar la reorganización racional de la sociedad puertorriqueña. No obstante, las viejas realidades del pasado como eran su vulnerabilidad económica y la desconfianza de la metrópoli en la capacidad de los puertorriqueños para participar plenamente en la administración del país, recrudecida ahora por un choque cultural abismal, mediatizó el proyecto de modernidad.

Es innegable que durante las primeras décadas del dominio colonial norteamericano hubo transformaciones en el desarrollo socioeconómico de la Isla, pero la pregunta clave es para qué y para quiénes estuvo encaminado este progreso. Cómo explicar la pauperización de la zona cafetalera, la emigración de miles de braceros, los [27].

74 Quintero Rivera, [4], pp. 134-142, Giusti CoRdero [27] y [66], Garcia- MuÑIZ,

R. I., $1997, \mathrm{n}^{\mathrm{o}} 211$ 
movimientos huelgarios que se sucedieron durante las primeras décadas del siglo 20 . No obstante a lo largo del tiempo cada uno de estos sectores desde su óptica particular buscaron formas de resistencias a la absorción política y cultural del poder metropolitano. La mayor parte de la elite política puertorriqueña que se aglutinó en torno a las ideologías autonomistas e independentistas inició un discurso de corte culturalista criollo, centrado en la defensa de la lengua española, la religión católica y las costumbres heredadas de la tradición hispánica. En un rejuego de forcejeos y acomodos - muchas veces contradictorio - esta elite contribuyó significativamente al fortalecimiento de la identidad nacional del país.

This article analyzes the "98" and its meanings, namely the fact that the Porto Rican elite acepted it as a path opened for developement of a modernizing project under US leadership. A re-organization of the country was expected as a consequence of the Empire's democratic liberalism. This was however resisted by the local economical, social and cultural conditions. Although some achievements must be recognized, it is necessary to analyze whom they benefited and what they were meant for. 